\title{
Informações Essenciais para Identificação, Avaliação e Manejo de Farmacodermias
}

\author{
Essential Information for Identifying, Evaluating and Managing Pharmacodermias
}

\author{
Isabella do Vale de Souza*a; Carolina Justus Buhrer Ferreira-Neto ${ }^{a}$
}

a Universidade Estadual de Ponta Grossa, PR, Brasil.

*E-mail: isabellavale92@gmail.com

\begin{abstract}
Resumo
Farmacodermias são definidas como qualquer mudança indesejada na estrutura ou função da pele, seus apêndices e membranas mucosas, e incluem todos os eventos adversos relacionados a erupções promovidas por medicamentos. Embora frequentes, a manifestação de forma muito parecida a outras doenças cutâneas comuns leva a dificuldades de direcionamento da avaliação. Caso o paciente esteja sob tratamento de diversos medicamentos, a determinação do medicamento causador da farmacodermia se torna complexa. É necessário ao profissional atuante em Farmacovigilância conhecimento científico atual e adequado para investigação. Embora as bases de dados e literatura forneçam informações com alto nível de evidência científica, por vezes a falta de dados atualizados e compilados compromete o processo de investigação de farmacodermias em curso. Durante a execução da Farmacovigilância, a consulta de documentos institucionais que norteiem a investigação - com embasamento científico e atualizado - favorece seu decurso. Nortear a identificação e manejo de graves reações adversas cutâneas a medicamentos foi o objetivo desta revisão narrativa realizada nas bases de dados científicas National Library of Medicine, Washington, DC (MEDLINE: Pubmed) e Scientific Electronic Library Online (SciELO). Foram recuperados 615 artigos científicos, que após seleção resultaram em 36 artigos relacionados à descrição e manejo de farmacodermias, escolhidos para elaboração desta revisão de literatura. Quadros informativos de consulta rápida foram elaborados para cada farmacodermia abordada, contendo informações essenciais para identificação, avaliação e sugestões de manejo. A existência de materiais de fácil consulta com embasamento científico adequado para execução da Farmacovigilância favorece a tomada de decisões e manejo de farmacodermias.
\end{abstract}

Palavras-chave: Farmacovigilância. Exantema, Efeitos Colaterais e Reações Adversas Relacionados a Medicamentos.

\begin{abstract}
Cutaneous adverse drug reactions (ADR) are defined as any undesired change in the structure or function of the skin, its appendages and mucous membranes, and include all adverse events related to drug-induced eruptions. Cutaneous manifestations of ADR, although frequent, are very similar to other common skin diseases, leading to difficulties in the process of their evaluation. If the patient is under a multidrug therapy, the determination of the drug causing the cutaneous ADR becomes complex. It is necessary for the professional working in Pharmacovigilance current scientific knowledge for adequate investigation of the case. There are databases and literature information with high level of scientific evidence, however sometimes the lack of updated and compiled data about this theme compromises the research process of in course cutaneous ADR. During Pharmacovigilance execution, consult of institutional documents that guide the investigation - with scientific and updated data - favor its course. The aim of this narrative review was to guide identification and management of adverse drug reactions, conducted in some scientific databases: National Library of Medicine, Washington, DC (MEDLINE: Pubmed) and Scientific Electronic Library Online (SciELO). Of the 615 scientific articles, 36 articles related to the description and management of cutaneous ADR were selected to elaborate this literature review. Quick reference information tables were prepared for each cutaneous ADR approached, containing essential information for identification, evaluation and suggestions for their management. Scientific and easy-to-read available materials for the Pharmacovigilance activity improves decision-making process and the management of cutaneous ADR.
\end{abstract}

Keywords: Pharmacovigilance. Exanthema. Drug-Related Side Effects and Adverse Reactions.

\section{Introdução}

Segurança do Paciente é o princípio fundamental dos cuidados de saúde. Estudos mostram que pacientes podem sofrer danos sérios à saúde durante o período de internação, como prolongamento da internação, dano permanente ou mesmo morte. Uma frágil cultura de segurança e qualidade do serviço, juntamente com procedimentos falhos de cuidado, contribui para o comprometimento do cuidado seguro ao paciente(OMS, 2017a).

Desde 2002, a estruturação da Rede Sentinela, que conta com hospitais voluntários como instituições participantes, permite busca, identificação e notificação dos eventos adversos e das queixas técnicas ligadas aos produtos sob Vigilância Sanitária, sendo um dos eixos de trabalho o gerenciamento prioritário de risco em medicamentos (BRASIL, 2017a).

Devido à necessidade de qualificação do cuidado em todo o território brasileiro, o Ministério da Saúde criou em 2013 o Programa Nacional de Segurança do Paciente (BRASIL, 2017a). Como parte das práticas adequadas para a prescrição segura de medicamentos, casos suspeitos de reações adversas a medicamentos (RAM) devem ser notificados ao Núcleo de Segurança do Paciente/Gerência de Riscos do estabelecimento de saúde (BRASIL, 2017b). 
A RAM é uma resposta nociva e não intencional à administração de um medicamento em doses usuais em humanos e pode sofrer influência de fatores individuais, como predisposição genética ou alterações metabólicas (OMS, 2017b). As RAMs são organizadas em dois subtipos, segundo sua previsibilidade: reações do tipo A, que são previsíveis a partir de propriedades farmacológicas conhecidas, e reações do tipo B, que são imprevisíveis ou síndromes inesperadas restritas a uma subpopulação vulnerável (ADKINSON et $a l, 2014)$. As farmacodermias são RAMs com manifestações cutâneas, frequentes, com prevalência de 2 a $3 \%$ em pacientes hospitalizados, sendo aproximadamente $2 \%$ destas reações severas e poucas são fatais (ROUJEAU; STERN, 1994). As manifestações cutâneas podem ser qualquer mudança indesejada na estrutura ou função da pele, seus apêndices e membranas mucosas. Assim, devem ser avaliadas pela Farmacovigilância (NAYAK; BASANTI, 2008), definida como ciência e atividades relativas à detecção, avaliação, compreensão e prevenção dos efeitos adversos ou outro problema relacionado com medicamentos (OMS, 2017c).

A manifestação de forma muito parecida a outras doenças cutâneas comuns leva a dificuldades de direcionamento da avaliação, e se o paciente está sob tratamento de diversos medicamentos, a determinação do medicamento causador da RAM é complexa. Uma avaliação racional e organizada é necessária e deve compreender a obtenção do histórico médico do paciente (incluindo exposições prévias a medicamentos), impressão clínica inicial da possível RAM com base na morfologia da lesão cutânea, diagnóstico diferencial da lesão cutânea, avaliação da exposição a medicamentos, análise da literatura, avaliação dos resultados laboratoriais e diagnósticos (como biópsia das lesões, p. ex.) e priorização do diagnóstico através da determinação de probabilidade de um medicamento induzir a farmacodermia investigada (NAYAK; BASANTI, 2008).

Devido aos diversos passos necessários para a avaliação de farmacodermias, há a necessidade de documentos que a facilitem, como guias para investigação e manejo. $\mathrm{O}$ uso de procedimentos padronizados permite o aumento da eficácia e da qualidade do processo, através da utilização de passos especificados de maneira sistemática, lógica, racional e baseada em evidências (KHALIL et al., 2011). Portanto, devido à necessidade de constante melhora das práticas clínicas visando a Segurança do Paciente, a compilação de informações através da revisão de literatura permite a orientação dos profissionais. Assim, a existência de documentos que norteiem a identificação e avaliação de Farmacodermias, se mostram como uma demanda existente para aperfeiçoamento da execução da Farmacovigilância.

\section{Desenvolvimento}

\subsection{Metodologia}

Uma revisão narrativa foi realizada nas bases de dados científicas National Library of Medicine, Washington, DC (MEDLINE: Pubmed) e Scientific Electronic Library Online (SciELO), contemplando todos os tipos de artigos científicos. A filtragem apresentou como critérios: tempo de publicação igual ou inferior a cinco anos, disponibilidade de texto integral, estudos realizados em humanos e publicados nos idiomas Inglês, Espanhol ou Português (última busca em 02 de agosto de 2018). Ao finalizar as pesquisas em cada base, as referências duplicadas foram excluídas. Os termos utilizados nas buscas foram "angioedema", "drug eruptions", "drug rashes", "erythroderma”, "photosensitivity”, "vasculitis" e "urticaria".

\subsubsection{Seleção de estudos}

Apartir da leitura dos títulos, a filtragem inicial dos estudos foi realizada, excluindo-se os artigos que não atendiam a descrição, relato, manejo ou avaliação clínica de farmacodermias. Em sequência, após leitura dos resumos, os artigos que descreviam relatos de caso de farmacodermias resultantes da administração de medicamentos não comercializados no Brasil foram excluídos. Estudos considerados elegíveis para inclusão foram os que apresentaram descrição detalhada de RAMs cutâneas como resultado da administração de medicamentos ou como estudo de um tipo específico de farmacodermia.

\subsubsection{Obtenção de dados}

Os artigos científicos escolhidos para inclusão foram avaliados quanto a incidência, tempo para início de manifestações cutâneas, achados cutâneos adicionais, descrição histopatológica, diagnóstico diferencial, mecanismo de lesão, tempo para resolução, sintomas sistêmicos associados, achados laboratoriais correlacionados, condições que podem oferecer risco, principais medicamentos promotores, taxa de mortalidade, complicações associadas e manejo recomendado de farmacodermias. Estas informações foram então compiladas em planilha elaborada no Microsoft Word $\AA$, acrescentando-se as informações de autores, ano de publicação e periódico.

\subsubsection{Informações disponíveis nos artigos selecionados}

Após filtragem de 615 artigos científicos por meio de leitura de título e resumo, 85 estudos foram considerados escolhidos para leitura integral, com apresentação de ao menos uma das informações selecionadas para avaliação. Após leitura integral dos estudos e compilação dos dados apresentados em planilha, 36 artigos foram selecionados para a compilação de dados necessários para a investigação pela Farmacovigilância por apresentarem informações consideradas como mínimas necessárias para a identificação e avaliação de farmacodermias (Quadro 1). 
Quadro 1 - Informações presentes nos artigos selecionados pela revisão de literatura

\begin{tabular}{|c|c|c|c|c|c|c|c|c|c|c|c|c|}
\hline \multirow[t]{2}{*}{$\begin{array}{l}\text { Informações sobre } \\
\text { farmacodermias }\end{array}$} & \multicolumn{2}{|c|}{$\begin{array}{c}\text { Eritroderma } \\
\qquad\left(\mathrm{N}=\mathbf{8}^{*}\right)\end{array}$} & \multicolumn{2}{|c|}{$\begin{array}{c}\text { Erupções } \\
\text { exante- } \\
\text { máticas a } \\
\text { medicamentos } \\
\left(\mathrm{N}=6^{*}\right) \\
\end{array}$} & \multicolumn{2}{|c|}{$\begin{array}{c}\text { Fotossensib. } \\
\quad(N=7)\end{array}$} & \multicolumn{2}{|c|}{$\begin{array}{c}\text { Vasculite } \\
\left(\mathrm{N}=7^{*}\right)\end{array}$} & \multicolumn{2}{|c|}{$\begin{array}{c}\text { Urticária } \\
\text { Angioedema } \\
(\mathbf{N}=10)\end{array}$} & \multicolumn{2}{|c|}{$\begin{array}{c}\text { Total artigos } \\
\quad(\mathbf{N}=\mathbf{3 6})\end{array}$} \\
\hline & $\mathbf{N}$ & $\%$ & $\mathbf{N}$ & $\%$ & $\mathbf{N}$ & $\%$ & $\mathbf{N}$ & $\%$ & $\mathbf{N}$ & $\%$ & $\mathbf{N}$ & $\%$ \\
\hline Incidência & 2 & 11,1 & 2 & 11,1 & 2 & 11,1 & 4 & 22,2 & 8 & 44,4 & 18 & 100 \\
\hline Tempo para início & 3 & 15,8 & 6 & 31,6 & 3 & 15,8 & 3 & 15,8 & 4 & 21,1 & 19 & 100 \\
\hline Manifestações cutâneas & 7 & 21,9 & 4 & 12,5 & 7 & 21,9 & 6 & 18,8 & 8 & 25,0 & 32 & 100 \\
\hline Achados cutâneos adicionais & 4 & 16,7 & 4 & 16,7 & 5 & 20,8 & 4 & 16,7 & 7 & 29,2 & 24 & 100 \\
\hline Descrição histopatológica & 3 & 27,3 & 2 & 18,2 & 2 & 18,2 & 4 & 36,4 & 0 & 0,0 & 11 & 100 \\
\hline Diagnóstico diferencial & 2 & 22,2 & 2 & 22,2 & 1 & 11,1 & 3 & 33,3 & 1 & 11,1 & 9 & 100 \\
\hline Mecanismo de lesão & 2 & 9,5 & 3 & 14,3 & 5 & 23,8 & 4 & 19,0 & 7 & 33,3 & 21 & 100 \\
\hline Tempo para resolução & 1 & 7,7 & 4 & 30,8 & 2 & 15,4 & 2 & 15,4 & 4 & 30,8 & 13 & 100 \\
\hline Manifestações sistêmicas & 6 & 28,6 & 2 & 9,5 & 0 & 0,0 & 6 & 28,6 & 7 & 33,3 & 21 & 100 \\
\hline Achados laboratoriais & 1 & 20,0 & 0 & 0,0 & 1 & 20,0 & 3 & 60,0 & 0 & 0,0 & 5 & 100 \\
\hline Condições que oferecem risco & 6 & 40,0 & 4 & 26,7 & 0 & 0,0 & 2 & 13,3 & 3 & 20,0 & 15 & 100 \\
\hline $\begin{array}{l}\text { Principais medicamentos } \\
\text { promotores }\end{array}$ & 7 & 25,0 & 4 & 14,3 & 6 & 21,4 & 4 & 14,3 & 7 & 25,0 & 28 & 100 \\
\hline Taxa de mortalidade & 1 & 50,0 & 0 & 0,0 & 0 & 0,0 & 0 & 0,0 & 1 & 50,0 & 2 & 100 \\
\hline Complicações associadas & 1 & 50,0 & 0 & 0,0 & 0 & 0,0 & 0 & 0,0 & 1 & 50,0 & 2 & 100 \\
\hline Manejo recomendado & 6 & 40,0 & 4 & 26,7 & 0 & 0,0 & 2 & 13,3 & 3 & 20,0 & 15 & 100 \\
\hline
\end{tabular}

*artigo utilizado para mais de uma farmacodermia.

Fonte: Dados da pesquisa.

Das categorias de informações elencadas para realização da revisão de literatura, verifica-se que nenhuma atinge a totalidade de artigos escolhidos. Informações sobre manifestações cutâneas estão presentes em 32 dos 36 artigos, sendo a informação com maior disponibilidade. Informações sobre taxas de mortalidade e complicações associadas às farmacodermias estão presentes em apenas dois artigos portanto, as informações com menor disponibilidade. Embora incipiente, a disponibilidade de artigos, dentre os avaliados, que tragam informações sobre descrição histopatológica (11 artigos) contribui para a possibilidade de utilizar resultados de biópsias das lesões como uma ferramenta mais específica de identificação da farmacodermia, tendo em vista que a descrição visual das lesões como ferramenta decisória de classificação está sujeita a interpretações pessoais do agente executor.

Considerando-se que o objetivo desta revisão é a compilação de informações que facilitem a identificação e avaliação de farmacodermias pelos profissionais envolvidos no processo de Farmacovigilância, a baixa disponibilidade de informações consideradas essenciais, mesmo após seleção criteriosa dos artigos selecionados, corrobora com a hipótese de necessidade de elaboração de materiais com informações atualizadas e seguras. Assim, as informações encontradas nos artigos alvo desta revisão são apresentadas e dão origem a quadros informativos sobre cada farmacodermia abordada. A opção por excluir da elaboração dos quadros as categorias informativas "Incidência", "Diagnóstico diferencial" e "Condições que oferecem risco" resulta da possibilidade de viés destas informações sobre o processo de identificação e avaliação da farmacodermia, sendo recomendada consulta à discussão em texto. "Descrição histopatológica" e "Mecanismo de lesão" não foram incluídos nos quadros informativos devido à complexidade de tais assuntos, que não foram passíveis de serem sintetizados sem perda de conteúdo.

\subsection{Eritroderma}

Eritroderma ou dermatite esfoliativa é uma condição inflamatória caracterizada por profunda vermelhidão da pele, envolvendo mais de $90 \%$ da área da superfície do corpo. Geralmente, demonstra uma extensa dermatite eritematosa com uma quantidade variável de descamação (ROWE et al., 2015). É relativamente raro, sendo observado em 35 a cada 10.000 das internações dermatológicas (OZUGUZ et al., 2014) e geralmente ocorre entre uma a três semanas após início da terapia ou exposição inicial e dentro de horas a dias em caso de reexposição (KUMAR et al., 2015). O início da descamação é tipicamente observado dentro de dois a seis dias após o início do eritema (MISTRY et al., 2015).

Eritema é a principal apresentação morfológica e, em alguns casos, está também associado a erosões (perda de epiderme com base epidérmica), crostas (serosas, sanguinolentas ou pustulares) e potenciais alterações nas unhas e cabelo. Prurido é observado em mais de $90 \%$ dos pacientes com eritroderma. Os indícios clínicos incluem alterações nas unhas e presença de ilhas de preservação (áreas bem demarcadas de pele preservada) com coloração amarelada na pele, além de hiperceratose das palmas das mãos e solas dos pés (MISTRY et al., 2015). Apresenta quadro histopatológico não específico, caracterizado por hiperqueratinose, paraqueratose, 
acantose e infiltrado inflamatório perivascular crônico rico em eosinófilos (MARZANO; BORGHI; CUGNO, 2016). Eritema é apresentado em outras doenças cutâneas e sistêmicas, como dermatites, doenças autoimunes, linfomas, leucemias, psoríases, infecções, ictiose e infestações (MISTRY et al., 2015). Em pacientes com queixas de febre, icterícia, erupção cutânea generalizada, insuficiência renal aguda e insuficiência hepática aguda, é necessário excluir a possibilidade de reação adversa a medicamento associada à eosinofilia e sintomas sistêmicos (Drug Reaction with Eosinophilia and Systemic Symptoms - DRESS) (SHARMA; GOVIL, 2013).

Atualmente, o mecanismo do eritroderma é desconhecido. Contudo, sabe-se que moléculas de adesão celular e seus ligantes desempenham um significante papel na interação endotélio-leucócitos. Impactam na ligação, transmigração e infiltração de linfócitos e células mononucleares durante inflamação, injúria ou estimulação imunológica (MARZANO; BORGHI; CUGNO, 2016). Comprometimento renal e anormalidades eletrolíticas são comumente observados e devem ser monitorados em pacientes com eritrodermia (TAN et al., 2014). Hipotermia é observada, devido ao aumento da taxa de fluxo dos vasos dérmicos, à perda protéica relacionada à descamação e ao aumento do volume plasmático, o que pode causar hemodiluição e edema grave (OZUGUZ et al., 2014). Alterações das funções hepática e renal, além de diminuição de nível sérico de albumina e alterações eletrolíticas (MISTRY et $a l ., 2015)$ e a resolução do quadro de eritroderma geralmente ocorre entre duas a seis semanas (ROWE et al., 2015).

Pacientes com eczema, psoríase, linfoma e leucemia apresentam maiores chances de eritroderma (GARG et al., 2015), sendo a condição mais comum em homens e em idades entre 41 e 61 anos (OZUGUZ et al., 2014). Os principais medicamentos associados a eritroderma são antimicrobianos, como antimicrobianos beta-lactâmicos (aztreonam, cefalosporinas, penicilinas), dapsona, gentamicina, indinavir, isoniazida, minociclina, trimetoprima e vancomicina, antihipertensivos/antiarrítmicos (amiodarona, bloqueadores dos canais de cálcio e tiazídicos), anticonvulsivantes (carbamazepina, fenitoína, lamotrigina e fenotiazinas), fármacos gastrintestinais (cimetidina e omeprazol) e outros, como codeína, dinitrato de isossorbida e quinidina (MISTRY et al., 2015). Relatos de casos envolvendo administração de medicamentos que pertencem às principais classes citadas também podem ser verificadas em literatura técnica, como a descrição de um quadro de eritrodermia por paciente do sexo feminino, de 58 anos, após uso contínuo de omeprazol ao longo de seis meses (ARONSON, 2006, p. 2616).

Desequilíbrio hidroeletrolítico, insuficiência cardíaca de alto débito, síndrome do desconforto respiratório agudo e infecções secundárias são algumas das complicações e as taxas de mortalidade descritas em literatura variam de 3,73\% a 64\%, dependendo da população estudada (MISTRY et al., 2015). O manejo clínico do eritroderma inclui reposição da perda de nutrientes, fluidos e eletrólitos e cuidados locais com a pele, como aplicação de emolientes e corticosteroides de baixa potência. Casos mais severos podem ser tratados com regime sistêmico de corticosteroide, como metilprednisolona endovenosa em dose de 0,5 a 1,0 mg/ $\mathrm{kg}$ diariamente, com descalonamento progressivo das doses. Antimicrobianos sistêmicos guiados por antibiogramas podem ser adicionados para controle de superinfecções bacterianas (MARZANO; BORGHI; CUGNO, 2016). As principais características clínicas e manejo recomendado do quadro de eritroderma se encontram no Quadro 2.

Quadro 2 - Principais características clínicas e manejo recomendado de eritroderma.

\begin{tabular}{|c|c|}
\hline \multicolumn{2}{|r|}{ Eritroderma } \\
\hline Tempo para início & $\begin{array}{l}\text { Uma a três semanas se exposição inicial; } \\
\text { horas a dias em caso de reexposição. } \\
\text { Descamação em dois a seis dias após o } \\
\text { início do eritema. }\end{array}$ \\
\hline $\begin{array}{l}\text { Manifestações } \\
\text { cutâneas }\end{array}$ & $\begin{array}{l}\text { Profunda vermelhidão da pele ( }>90 \% \text { da } \\
\text { área de superfície corporal - ASC). Extensa } \\
\text { dermatite eritematosa com uma quantidade } \\
\text { variável de descamação. }\end{array}$ \\
\hline $\begin{array}{l}\text { Achados cutâneos } \\
\text { adicionais }\end{array}$ & $\begin{array}{l}\text { Eritema associado a erosões (perda de } \\
\text { epiderme com base epidérmica), crostas } \\
\text { (serosas, sanguinolentas ou pustulares) e } \\
\text { prurido. Alterações nas unhas e presença } \\
\text { de ilhas de preservação com coloração } \\
\text { amarelada na pele; hiperceratose das palmas } \\
\text { das mãos e solas dos pés. }\end{array}$ \\
\hline $\begin{array}{l}\text { Tem } \\
\text { reso }\end{array}$ & Duas a seis semanas. \\
\hline $\begin{array}{l}\text { Manifestações } \\
\text { sistêmicas } \\
\text { associadas }\end{array}$ & $\begin{array}{l}\text { Comprometimento renal e anormalidades } \\
\text { eletrolíticas. Hipotermia, hemodiluição e } \\
\text { edema grave também podem ocorrer. }\end{array}$ \\
\hline $\begin{array}{l}\text { Achados } \\
\text { Laboratoriais }\end{array}$ & $\begin{array}{l}\text { Alterações das funções hepática e renal; } \\
\text { diminuição de nível sérico de albumina e } \\
\text { alterações eletrolíticas. }\end{array}$ \\
\hline $\begin{array}{l}\text { Principais classes } \\
\text { de medicamentos } \\
\text { promotores }\end{array}$ & $\begin{array}{l}\text { Antimicrobianos, anti-hipertensivos, } \\
\text { antiarrítmicos, anticonvulsivantes } \\
\text { fármacos com ação gastrintestinal. }\end{array}$ \\
\hline Mortalidade & $\begin{array}{l}\text { De } 3,73 \% \text { a } 64 \% \text {, dependendo da população } \\
\text { atingida. }\end{array}$ \\
\hline $\begin{array}{l}\text { Complicações } \\
\text { associadas }\end{array}$ & $\begin{array}{l}\text { Desequilíbrio hidroeletrolítico, } \\
\text { insuficiência cardíaca de alto débito, } \\
\text { síndrome do desconforto respiratório agudo } \\
\text { e infecções secundárias. }\end{array}$ \\
\hline $\begin{array}{l}\text { Manejo } \\
\text { recomendado }\end{array}$ & $\begin{array}{l}\text { Reposição da perda de nutrientes, fluidos e } \\
\text { eletrólitos. Cuidados locais coma pele, como } \\
\text { aplicação de emolientes e corticosteroides } \\
\text { de baixa potência. Em casos severos, } \\
\text { regime sistêmico de corticosteroide com } \\
\text { descalonamento progressivo das doses. }\end{array}$ \\
\hline
\end{tabular}

Fonte: Dados da pesquisa.

\subsection{Erupções exantemáticas por medicamentos}

As erupções exantemáticas são as erupções mais comuns induzidas por fármacos, ocorrendo em 1 a $5 \%$ dos usuários iniciantes da maioria dos medicamentos (HEELAN; SHEAR, 2013). Normalmente, ocorrem entre quatro a quatorze dias após o início de um medicamento (IJAZ; MCMULLEN; SINGH, 2015) e se apresentam como máculas e pápulas eritematosas (embora as lesões possam ser polimórficas), que 
começam no tronco e se espalham para fora. As membranas mucosas são geralmente poupadas (SWANSON; COLVEN, 2015).

As erupções apresentam-se como máculas e pápulas corde-rosa e salmão, generalizadas, que geralmente se iniciam na cabeça, pescoço ou tronco superior. Então, se espalham simetricamente para baixo e se tornam confluentes; podem apresentar prurido (SONG; SIDBURY, 2014). Verifica-se histologicamente, a presença de dermatite de interface com alterações vacuolares de queratinócitos na camada celular basal e um infiltrado de células mononucleares dérmicas superiores com alguns eosinófilos. A análise imuno-histoquímica revela uma superexpressão de várias citocinas, como interleucina (IL)-5 e IL-13, que estão correlacionadas com a eosinofilia da pele e do sangue, além de outras moléculas efetoras, como a perforina e a granzima B (MARZANO; BORGHI; CUGNO, 2016). Os diagnósticos diferenciais incluem infecções virais, principalmente indistinguíveis das RAMs cutâneas e muito frequentes em crianças (Epstein-Barr vírus, Herpesvírus humano-6 e adenovírus), infecções bacterianas (Streptococcus pyogenes), artrite sistêmica juvenil (doença de Still), Síndrome de Kawasaki, doença do enxerto contra hospedeiro, receptores de transplante de células-tronco hematopoiéticas e eritema multiforme (NOGUERA-MOREL; HERNÁNDEZMARTÍN; TORRELO, 2014).

Embora o mecanismo patológico das erupções ainda não esteja completamente compreendido, acredita-se que um mecanismo imune tardio, mediado por células do tipo IV envolvendo linfócitos $\mathrm{T}$ específicos de fármacos, seja relevante (MARZANO; BORGHI; CUGNO, 2016). Outras manifestações podem incluir febre baixa e prurido e a evolução para resolução geralmente leva cerca de duas semanas, com o exantema tornando-se vermelho acastanhado e resolvendo com descamação (NOGUERA-MOREL; HERNÁNDEZMARTÍN; TORRELO, 2014). A incidência é aumentada na presença de infecções virais, como em casos de pacientes com infecções por vírus da imunodeficiência humana (HIV), e em pacientes que realizaram transplante de medula óssea. As classes mais comuns de medicamentos promotores incluem penicilinas, sulfonamidas, cefalosporinas e medicamentos anticonvulsivantes (HEELAN; SHEAR, 2013). A classe de medicamentos anticonvulsivantes é confirmada por Aronson (2003) como promotora de RAMs cutâneas de gravidades variáveis, incluindo erupções exantemáticas, que costumam aparecer durante as primeiras semanas de tratamento estão entre as causas mais comuns de abstinência precoce de carbamazepina, fenitoína, oxcarbazepina, barbitúricos e lamotrigina.

Em alguns casos as erupções podem progredir para eritroderma ou reações mais graves. Se o fármaco suspeito é de importância terapêutica essencial para o paciente, deve ser sugerido um fármaco estruturalmente diferente, a fim de evitar reação cruzada em tratamento futuro (MARZANO;
BORGHI; CUGNO, 2016). Casos leves podem ser tratados apenas de forma sintomática com anti-histamínicos, mas se a erupção for muito sintomática, os corticosteroides tópicos podem ajudar a reduzir a inflamação e o prurido da pele. Quando a reação é moderada a grave, os corticosteroides sistêmicos podem ser úteis, geralmente $1 \mathrm{mg} / \mathrm{kg} / \mathrm{dia}$ até a resolução com redução dos cuidados (NOGUERA-MOREL; HERNÁNDEZ-MARTÍN; TORRELO, 2014). A consulta rápida das características e manejo possível de quadros de erupções exantemáticas por medicamentos está disponível no Quadro 3.

Quadro 3 - Principais características clínicas e manejo recomendado de erupções exantemáticas por medicamentos.

\begin{tabular}{|c|c|}
\hline \multicolumn{2}{|c|}{ Erupções Exantemáticas por Medicamentos } \\
\hline Tempo para início & $\begin{array}{l}\text { De quatro a quatorze dias após o início de } \\
\text { novo medicamento. }\end{array}$ \\
\hline $\begin{array}{l}\text { Manifestações } \\
\text { cutâneas }\end{array}$ & $\begin{array}{l}\text { Máculas e pápulas eritematosas, com início } \\
\text { no tronco. As membranas mucosas são } \\
\text { geralmente poupadas. }\end{array}$ \\
\hline $\begin{array}{l}\text { cutâneos } \\
\text { is }\end{array}$ & $\begin{array}{l}\text { As máculas e pápulas apresentam cor } \\
\text { de rosa ou salmão, são generalizadas, e } \\
\text { geralmente se iniciam na cabeça, pescoço } \\
\text { ou tronco superior. Prurido. Resolução } \\
\text { do exantema com coloração vermelha } \\
\text { acastanhada e descamação. }\end{array}$ \\
\hline & Cerca de \\
\hline $\begin{array}{l}\text { stações } \\
\text { cas } \\
\text { das }\end{array}$ & estar presente. \\
\hline $\begin{array}{l}\text { os } \\
\text { oriais }\end{array}$ & $\begin{array}{l}\text { Não encontrados nas referências } \\
\text { consultadas. }\end{array}$ \\
\hline $\begin{array}{l}\text { Principais classes } \\
\text { de medicamentos } \\
\text { promotores }\end{array}$ & $\begin{array}{l}\text { Antimicrobianos, como } \begin{array}{r}\text { penicilinas, } \\
\text { sulfonamidas } \\
\text { antiepilépticos. }\end{array} \\
\text { cefalosporinas; }\end{array}$ \\
\hline Mortalidade & Não encontrada nas referências consultadas. \\
\hline $\begin{array}{l}\text { cações } \\
\text { las }\end{array}$ & $\begin{array}{l}\text { Progressão para eritroderma ou reações } \\
\text { mais graves. }\end{array}$ \\
\hline $\begin{array}{l}\text { Manejo } \\
\text { recomendado }\end{array}$ & $\begin{array}{l}\text { Suspensão do fármaco promotor, } \\
\text { com sugestão de troca por fármaco } \\
\text { estruturalmente diferente. Casos leves: anti- } \\
\text { histamínicos; corticosteróides tópicos em } \\
\text { caso de prurido intenso. Reação moderada } \\
\text { a grave: corticosteroides sistêmicos, } 1 \mathrm{mg} / \\
\mathrm{kg} / \text { dia. }\end{array}$ \\
\hline
\end{tabular}

Fonte: Dados da pesquisa.

\subsection{Fotossensibilidade}

Correspondendo a $8 \%$ das farmacodermias reportadas, a fotossensibilidade pode ser resultado de fotoalergia ou fototoxicidade; o início das manifestações na fotoalergia se dá 24 horas ou mais após exposição inicial ao fotoalérgeno, enquanto na fototoxicidade, minutos a horas após exposição à luz do sol com sensação de queimação imediata, seguida por surgimento de pápulas em uma hora e eritema entre 24 a 48 horas (MONTEIRO; RATO; MARTINS, 2016). As manifestações cutâneas são de distribuição tipicamente fotossensível das lesões, com envolvimento do rosto, parte superior do tronco e região em $\mathrm{V}$ do pescoço, dorso das mãos 
e antebraços extensores (GROSSBERG, 2013).

As reações fototóxicas são semelhantes a queimaduras solares, eritema, edema com ou sem bolhas, queimação e dor, demarcadas pela exposição à luz solar; já as reações fotoalérgenas, são eczematosas e com prurido (HONARI, 2014). Presença de eritema em fotodermatoses ocorre apenas em caso de fototoxicidade. Vesículas são observadas em casos de fototoxicidade e fotoalergia (CHOI; KANNAN; LIM, 2014). Podem ser encontrados níveis anormais de porfirina, indicando pseudoporfiria. O quadro histopatológico da fotoalergia revela espongiose epidérmica, vesiculações, exocitose de linfócitos na epiderme e infiltrados inflamatórios perivasculares são observados; na fototoxicidade, há necrose de queratinócitos epidérmicos com infiltrados dérmicos de linfócitos e neutrófilos (MONTEIRO; RATO; MARTINS, 2016).

Reações fototóxicas são não-imunológicas e podem ocorrer em qualquer indivíduo exposto a agentes químicos fototóxicos suficientes e apropriados comprimentos de onda de luz, sendo promovidas por dano direto celular, dano ao DNA, espécies reativas de oxigênio e inflamação. Reações fotoalérgicas são promovidas por processo de hipersensibilidade mediado por células T (reações tipo IV de Gell e Coombs) em indivíduos previamente sensibilizados com o agente promotor. Fotoalérgenos são substâncias que absorvem luz e formam espécies que se ligam covalentemente a proteínas para transformá-las em alérgenos plenos (HONARI, 2014). Em caso de fotoalergia, a resolução do quadro se dá após descontinuação do fotoalérgeno; no entanto, em raros casos há persistência, com desenvolvimento de dermatite actínica crônica (MONTEIRO; RATO; MARTINS, 2016). Em quadros de fototoxicidade, há resolução espontânea das lesões com descamação, no entanto, hiperpigmentação pósinflamatória pode ocorrer (RAMBHATLA et al., 2015).

Os principais medicamentos promotores de reações de fotossensibilidade são ansiolíticos (alprazolam), antiarrítmicos (amiodarona), antidepressivos (amitriptilina, imipramina, clomipramina, escitalopram, paroxetina, sertralina, citalopram, venlafaxina), antidislipidêmicos (sinvastatina, fenofibrato), antifúngicos (cetoconazol, itraconazol), antiinflamatórios não esteroidais (cetoprofeno, ibuprofeno), antipsicóticos (clorpromazina, olanzapina, clozapina), antirretrovirais (efavirenz), antituberculosos (isoniazida), bloqueadores dos canais de cálcio (anlodipino, nifedipino, diltiazem), cefalosporinas de terceira geração (ceftazidima), derivados de sulfonamida, diuréticos (hidroclorotiazida, indapamida, furosemida), fluoroquinolonas, inibidores da enzima conversora de angiotensina (captopril, enalapril), outros antihipertensivos (metildopa), outros medicamentos (ranitidina, carbamazepina, clopidogrel), tetraciclinas (doxiciclina) e tópicos (aciclovir, hidrocortisona, protetores solares, diclofenaco). Como manejo, é recomendada a interrupção do tratamento com o fármaco suspeito. Quando a interrpução não é possível, recomenda-se fotoproteção adequada (comportamento, ambiente, roupas e proteção solar). Aronson (2013, p. 92) sugere que a capacidade de fotossensibilidade pode estar relacionada à natureza lipossolúvel do fármaco, como observado em caso envolvendo uso crônico de alprazolam. Para fármacos com curto tempo de meia vida, o ajuste do horário de administração pode adaptar o pico de concentração plasmática do fármaco em relação à fotoexposição (DAWE; IBBOTSON, 2014; GÓMEZBERNAL et al., 2014). Em caso de fotoalergia, é essencial a identificação e retirada do fotoalérgeno, além de fotoproteção UVA e UVB, com uso de corticosteroides tópicos e antihistamínicos para tratamento dos sintomas. Fototoxicidade exige a retirada do agente fototóxico, fotoproteção e corticosteroides tópicos (RAMBHATLA et al., 2015). O Quadro 4 apresenta as informações de características e manejo de casos de fotossensibilidade.

Quadro 4 - Principais características clínicas e manejo recomendado de fotossensibilidade.

\begin{tabular}{|c|c|}
\hline \multicolumn{2}{|r|}{ Fotossensibilidade } \\
\hline Temp & $\begin{array}{l}\text { Em caso de fotoalergia, } 24 \text { horas ou } \\
\text { mais após exposição inicial; casos de } \\
\text { fototoxicidade iniciam-se dentro de } \\
\text { minutos a horas após exposição à luz. }\end{array}$ \\
\hline $\begin{array}{l}\text { Manifesta } \\
\text { cutâneas }\end{array}$ & $\begin{array}{l}\text { Lesões fotoalérgenas são eczematosas } \\
\text { e apresentam prurido, enquanto lesões } \\
\text { fototóxicas são semelhantes a queimaduras } \\
\text { solares. Ambas apresentam distribuição } \\
\text { fotossensível em rosto, parte superior do } \\
\text { tronco e região em V do pescoço, dorso das } \\
\text { mãos e antebraços extensores. }\end{array}$ \\
\hline $\begin{array}{l}\text { Achado } \\
\text { adicion }\end{array}$ & $\begin{array}{l}\text { Fototoxicidade podem apresentar eritema, } \\
\text { edema com ou sem bolhas, queimação e } \\
\text { dor, demarcadas pela exposição à luz solar. }\end{array}$ \\
\hline $\begin{array}{l}\text { Ten } \\
\text { reso }\end{array}$ & $\begin{array}{l}\text { Fototoxicidade apresenta resolução } \\
\text { espontânea com ocorrência de descamação; } \\
\text { após retirada do fotoalérgeno há resolução } \\
\text { do quadro de fotoalergia. }\end{array}$ \\
\hline $\begin{array}{l}\text { Manifestações } \\
\text { sistêmicas } \\
\text { associadas }\end{array}$ & $\begin{array}{l}\text { Não encontradas nas referências } \\
\text { consultadas. }\end{array}$ \\
\hline $\begin{array}{l}\text { Ach } \\
\text { labo }\end{array}$ & $\begin{array}{l}\text { Possibilidade de níveis anormais de } \\
\text { porfirina. }\end{array}$ \\
\hline $\begin{array}{l}\text { Principais classes } \\
\text { de medicamentos } \\
\text { promotores }\end{array}$ & $\begin{array}{l}\text { Diversas, como ansiolíticos, antiarrítmicos, } \\
\text { antidepressivos, antidislipidêmicos, } \\
\text { antifúngicos, antiinflamatórios não } \\
\text { esteroidais, antimicrobianos, antipsicóticos, } \\
\text { antirretrovirais, antituberculosos, } \\
\text { bloqueadores dos canais de cálcio, } \\
\text { diuréticos, fluroquinolonas, inibidores da } \\
\text { enzima conversora de angiotensina. }\end{array}$ \\
\hline Mortalidade & Não encontrada nas referências consultadas. \\
\hline $\begin{array}{l}\text { Complicações } \\
\text { associadas }\end{array}$ & $\begin{array}{l}\text { Hiperpigmentação pós-inflamatória em } \\
\text { pacientes com fototoxicidade. }\end{array}$ \\
\hline $\begin{array}{l}\text { Manejo } \\
\text { recomendado }\end{array}$ & $\begin{array}{l}\text { Retirada do fármaco promotor, fotoproteção } \\
\text { adequada e correção do horário de } \\
\text { administração. Corticosteroides tópicos e } \\
\text { anti-histamínicos para alívio. }\end{array}$ \\
\hline
\end{tabular}

Fonte: Dados da pesquisa. 


\subsection{Vasculite induzida por medicamentos}

De acordo com Adkinson e colaboradores (2014), vasculite é geralmente definida como inflamação dos vasos sanguíneos, resultando em dano tecidual local ou remoto. Os vasos sanguíneos envolvidos podem ser pequenos, como as vênulas pós-capilares da pele, ou grandes, como a artéria temporal ou o arco da aorta. Vasculite induzida por medicamento corresponde a $20 \%$ das vasculites cutâneas, sendo a mais comum das vasculites de pequenos vasos (BHARDWAJ et al., 2014). Aparecimento tende entre sete a dez dias após a exposição a um medicamento (MICHELETTI; WERTH, 2015) e geralmente, se manifesta com púrpura da pele, artralgia e mialgia (ROUJEAU et al., 2014).

A púrpura cutânea pode continuar sendo a única característica ou evoluir para variadas manifestações, incluindo pápulas, nódulos ou placas, bem como pústulas ou vesículas/bolhas; estas últimas podem evoluir para lesões ulcerativas-necróticas, que curam com hiperpigmentação pósinflamatória (MARZANO; BORGHI; CUGNO, 2016). O número de lesões pode variar de dezenas a centenas. Novas lesões podem aparecer diariamente até que o tratamento seja iniciado ou o promotor seja retirado (MICHELETTI; WERTH, 2015). Outros achados cutâneos incluem o livedo reticularis, uma mancha vermelha ou azulada da pele com padrão de rede e lesões de urticária. As lesões geralmente ocorrem em áreas propensas a estase, particularmente nas pernas; por vezes, podem se estender para envolver os tornozelos, a parte inferior do tronco e as extremidades superiores. Queimação, dor e mais raramente prurido podem ocorrer (MARZANO; BORGHI; CUGNO, 2016).

As alterações histológicas estão confinadas aos pequenos vasos da derme superficial e média e geralmente estão associadas a um padrão adicional de reações inflamatórias, como a interface vacuolar, padrões espongióticos e psoriasiformes. As alterações vasculíticas podem ser histologicamente semelhantes à vasculite leucocitoclástica, vasculite linfocítica (edema endotelial e infiltrado linfocitário perivascular) e vasculite granulomatosa (agregados perivasculares de células epitelioides e gigantes). A vasculite leucocitoclástica induzida por fármacos apresenta necrose das paredes dos vasos sanguíneos cutâneos, leucocitoclasia, infiltração neutrofílica, deposição de fibrina e hemorragia, é o tipo histológico mais comum e deve ser distinguida da vasculite leucocitoclástica associada à doença sistêmica. Neste último, as alterações vasculíticas geralmente envolvem os vasos sangüíneos na derme e no tecido subcutâneo médio e profundo. A vasculite pode envolver as arteríolas e pequenas artérias (HUSSEIN, 2016).

O principal mecanismo patogenético é uma reação imuno-complexa, denominada reação de Gell e Coombs tipo 3. Interagindo com o sistema complemento, a deposição do complexo imune induzido por fármacos estimula a produção de citocinas pró-inflamatórias, quimiocinas e aminas vasoativas, que induzem a expressão de moléculas de adesão nas células endoteliais. Isso leva ao recrutamento de neutrófilos. Degranulação e destruição destas células com liberação de colagenases e elastases e geração de espécies reativas de oxigênio, em última análise, resultam em inflamação e necrose fibrinóide das paredes dos vasos. Os linfócitos $\mathrm{T}$ CD4+ atuam nas citocinas secretoras da fisiopatologia de vasculite cutânea de pequenos vasos (notavelmente IL-1, IFN- $\gamma$ e TNF- $\alpha$ ) e recrutamento de células T citotóxicas CD8 +, células B e células natural killer (MARZANO; BORGHI; CUGNO, 2016). Vasculite de pequenos vasos também pode ser causada por uma doença subjacente do tecido conjuntivo, como lúpus eritematosos sistêmico, Síndrome de Sjögren, artrite reumatoide ou dermatomiosite (MICHELETTI; WERTH, 2015).

O envolvimento extra-cutâneo está presente em cerca de 39,8 a 56,1\% dos pacientes com vasculite cutânea. As principais manifestações extra-cutâneas são artralgia/ artrite (21 a 50\%), envolvimento gastrointestinal (7 a 14\%) e alterações renais (15 a 38\%). Alterações renais resultantes de vasculite podem causar insuficiência renal e oligúria. Os achados histológicos são vasculites e necrose tubular com depósitos fibrinóides (ARONSON, 2006, p. 80-81). $\mathrm{O}$ envolvimento pulmonar geralmente é encontrado em menos de $10 \%$ dos casos e envolvimento ocular e do sistema nervoso em menos de 5\% (PINA; BLANCO; GONZÁLEZGAY, 2013). VHS (velocidade de hemossedimentação) acima de $50 \mathrm{~mm} / \mathrm{h}$ pode estar presente, sendo indicativo de envolvimento sistêmico. ANA (anticorpo anti-nuclear) ou FAN (fator antinuclear) positivos sugerem a presença de desordem subjacente do tecido conectivo (BHARDWAJ et al., 2014). Pacientes afetados por vasculite induzida por medicamentos são muitas vezes positivos para anticorpos anticitoplasma de mieloperoxidase e antineutrófilo (MPOANCAs) e podem apresentar anticorpos anti-histamínicos, altos níveis de anticorpos anticardiolipina $\mathrm{M}$ e baixos valores de C4 (ROUJEAU et al., 2014). Quando ocorre envolvimento renal, verifica-se hematúria, proteinúria e aumento da creatinina sérica. Avanços na imagem podem ajudar a avaliar os órgãos envolvidos e mostrar infartos teciduais, edema e anomalias vasculares, suportando a presença de uma doença multissistêmica compatível com vasculite (GRAU, 2015).

Tratamentos de longo prazo com drogas antitireoidianas, fornecendo características de uma condição lúpica, estão relacionados com possível envolvimento renal e pulmonar (ROUJEAU et al., 2014). Antimicrobianos, diuréticos, AINES, anticonvulsivantes, antipsicóticos, inibidores do TNF- $\alpha$, rituximabe e IFN- $\beta$ são os principais fármacos implicados (MARZANO; BORGHI; CUGNO, 2016). Estimase que de $8 \%$ a $10 \%$ dos pacientes desenvolva vasculite crônica ou recorrente. Apesar disso, a maioria dos casos apresenta bom prognóstico geral (MICHELETTI; WERTH, 2015). Na ausência de envolvimento renal ou pulmonar, a interrupção do agente causal geralmente é suficiente. 
Utilização de corticosteróides sistêmicos é justificada em caso de envolvimento de órgãos, com uso de prednisona ou equivalente em uma dose diária de $1 \mathrm{mg} / \mathrm{kg}$ por quatro a oito semanas (ROUJEAU et al., 2014). As principais características clínicas e manejo recomendado do quadro de vasculite induzida por medicamentos apresentam-se no Quadro 5.

Quadro 5 - Principais características clínicas e manejo recomendado de vasculite induzida por medicamentos.

\begin{tabular}{|c|c|}
\hline \multicolumn{2}{|c|}{ Vasculite Induzida por Medicamentos } \\
\hline ra & $\begin{array}{l}\text { Sete a dez dias após a exposição a fármaco } \\
\text { promotor. }\end{array}$ \\
\hline $\begin{array}{l}\text { Mani } \\
\text { cutân }\end{array}$ & $\begin{array}{l}\text { Púrpura cutânea, que pode evoluir com } \\
\text { pápulas, nódulos ou placas, pústulas ou } \\
\text { vesículas-bolhas. Distribuição de dezenas } \\
\text { a centenas de lesões em áreas propensas a } \\
\text { estase. }\end{array}$ \\
\hline $\begin{array}{l}\text { Achados cutâneos } \\
\text { adicionais }\end{array}$ & $\begin{array}{l}\text { Lesões ulcerativas-necróticas a partir } \\
\text { de vesículas-bolhas; livedo reticulares. } \\
\text { Queimação, dor e prurido. }\end{array}$ \\
\hline $\begin{array}{l}\text { Ten } \\
\text { res }\end{array}$ & $\begin{array}{l}\text { Duas a três semanas, com hiperpigmentação } \\
\text { pós-inflamatória. }\end{array}$ \\
\hline $\begin{array}{l}\text { Manifestações } \\
\text { sistêmicas } \\
\text { associadas }\end{array}$ & $\begin{array}{l}\text { Artralgia, artrite, envolvimento } \\
\text { gastrintestinal, pulmonar, renal e do sistema } \\
\text { nervoso. }\end{array}$ \\
\hline $\begin{array}{l}\text { Ach } \\
\text { labo }\end{array}$ & $\begin{array}{l}\text { VHS > } 50 \mathrm{~mm} / \mathrm{h} \text { é indicativo de } \\
\text { envolvimento sistêmico. Hematúria, } \\
\text { proteinúria e aumento da creatinina sérica } \\
\text { em caso de envolvimento renal. }\end{array}$ \\
\hline $\begin{array}{l}\text { Principais classes } \\
\text { de medicamentos } \\
\text { promotores }\end{array}$ & $\begin{array}{l}\text { Anticonvulsivantes, antiiinflamatórios não } \\
\text { esteroidais, antimicrobianos, antipsicóticos, } \\
\text { diuréticos e inibidores do TNF- } \alpha \text {. }\end{array}$ \\
\hline M & la nas referênc \\
\hline $\begin{array}{l}\text { cações } \\
\text { das }\end{array}$ & $\begin{array}{l}\text { Desenvolvimento de vasculite crônica } \\
\text { recorrente. }\end{array}$ \\
\hline $\begin{array}{l}\text { Manejo } \\
\text { recomendado }\end{array}$ & $\begin{array}{l}\text { Interrupção do fármaco promotor. Em caso } \\
\text { de envolvimento sistêmico, prednisona ou } \\
\text { equivalente em uma dose diária de } 1 \mathrm{mg} / \mathrm{kg} \\
\text { por quatro a oito semanas. }\end{array}$ \\
\hline
\end{tabular}

Fonte: Dados da pesquisa.

\subsection{Urticária e Angioedema}

A urticária afeta pessoas de todas as idades e é bastante comum, sendo os sintomas da urticária crônica com aqueles observados em pacientes que sofrem reações adversas a medicamentos (ADKINSON, 2014, p. 575). A prevalência global de urticária é estimada entre 1 a $1,5 \%$ na população em geral e 3\% em pacientes dermatológicos. Urticária espontânea aguda apresenta prevalência ao longo da vida de 15 a 20\%, representando a forma mais comum (WEDI et al., 2014). Angioedema ocorre em aproximadamente $15 \%$ da população geral (FELDER et al., 2014). Angioedema concomitante à urticária espontânea aguda ocorre em mais da metade dos casos (WEDI et al., 2014) e angioedema isolado sem urticária associada representa $10 \%$ dos casos (BOUILLET et al., 2014). Angioedema induzido por bradicinina ocorre em
$0,1 \%$ a $0,7 \%$ dos pacientes para os quais que são prescritos inibidores da enzima conversora de angiotensina (iECA). A maior incidência, aproximadamente $50 \%$, surge na primeira semana de tratamento (COLLINS-YODER, 2016).

A grande maioria dos pacientes desenvolve os sintomas de urticária espontânea aguda dentro de minutos, tipicamente menos de 30 minutos, após a administração do medicamento promotor (KOWALSKI; WOESSNER; SANAK; 2015). Um terço em cada 2500 casos de angioedema induzido por iECA é apresentado na primeira semana e dois terços durante os primeiros 90 dias de início do tratamento. No entanto, embora menos freqüente, o início dos sintomas pode ser retardado em até sete a dez anos de uso de iECA (CAMPO et al., 2013). Em episódios de urticária espontânea aguda, o paciente pode descrever o aparecimento súbito de lesões elevadas ou pápulas deformas e tamanhos variados, apresentando virtualmente em qualquer parte do corpo. As lesões são geralmente descritas como intensamente pruriginosas. As lesões também podem ser descritas como picadas, dando uma sensação de alfinetes e agulhas, ou mesmo dolorosa (JAFILAN; JAMES, 2015). Angioedema, quando associado à urticária, geralmente afeta o rosto de lábios, extremidades e/ou genitálias (LOSAPPIO et al., 2014). Angioedema mediado por bradicinina geralmente envolve inchaço não prurítico da pele e de membranas mucosas em diferentes localizações, preferencialmente afetando lábios, língua, boca, laringe, faringe ou região periorbital (CAMPO et al., 2013).

Prurido é o sintoma predominante da urticária espontânea aguda. Outros sinais característicos incluem pápulas e erupções que variam em tamanho. Em alguns casos, a urticária pode ocorrer concomitantemente com angioedema, que tipicamente envolve a derme profunda e gordura subcutânea, como em tecido periorbital, lábios, língua e mãos. $\mathrm{O}$ angioedema associado à urticária pode persistir por até 72 horas e geralmente é acompanhado por sensação de queimação e/ou dor moderada. Prurido não é comum em angioedema (KULTHANAN et al., 2016). Angioedema associado à bradicinina não está associada a pápulas. Por vezes, é precedido por uma erupção cutânea reticulada chamada eritema marginatum, que não deve ser confundida com uma erupção urticária. Isso significa que um angioedema sem urticária associada não é necessariamente mediado pela bradicinina (BOUILLET et al., 2014), uma vez que pode haver angioedema mediado por histamina e não associado à urticária. Erupções urticariformes acabam por se resolver em poucos dias, sem alterações residuais na pele. Na urticária espontânea aguda, as lesões geralmente desaparecem em menos de 24 horas, com duração inferior a seis semanas (JAFILAN; JAMES, 2015). Angioedema associado à urticária frequentemente persiste por um a três dias e tende a ser doloroso (WEDI et al., 2014). O angioedema mediado pela bradicinina geralmente tem um curso mais prolongado (FELDER et al., 2014).

A urticária resulta de uma cascata envolvendo eventos 
imunológicos. Começa com a degranulação de mastócitos, estímulo para a liberação de outros mediadores celulares. Esses mediadores incluem histamina, bradicinina, leucotrienos, prostaglandinas e outras substâncias vasodilatadoras. Estes causam o extravasamento de células plasmáticas na derme, resultando na característica de lesões urticariformes edematosas, pruriginosas e elevadas. Alguns medicamentos, como narcóticos e antimicrobianos, podem induzir diretamente a degranulação de mastócitos, levando a lesões urticariformes na pele. As causas podem ser classificadas como mediadas por IgE, mediadas por bradicinina, mediadas por complemento e não imunológicas. $\mathrm{O}$ angioedema associado à histamina é essencialmente urticária que ocorre na mucosa e camadas mais profundas da pele, causado pelo extravasamento de líquido entre as células endoteliais dos vasos sanguíneos (BOUILLET et al., 2014). O angioedema mediado por bradicinina (associado a iECA) não está associado à urticária, e o mecanismo patogênico parece estar ligado principalmente à diminuição da degradação da bradicinina, que dilata os vasos sanguíneos, media a inflamação, aumenta a permeabilidade vascular e ativa os nociceptores (BERTAZZONI et al., 2013).

$\mathrm{O}$ angioedema associado à bradicinina pode estar localizada na região abdominal e pode causar cenários suboclusivos recorrentes com recuperação espontânea após 48 a 72 horas. Eles são acompanhados de dor intensa (escala analógica visual de dor maior do que 7 em 69\% dos casos), às vezes por distúrbios da pressão arterial, náuseas e vômitos, muitas vezes com diarreia grave. Imagens médicas (scan ou ultrassonografia) revelam ascites e/ou edema das paredes do trato digestivo. A associação de angioedema facial com edemas periféricos e crises abdominais é altamente específica para a ocorrência de angioedema associado à bradicinina (BOUILLET et al., 2014). Diversos fatores de risco foram descritos para angioedema induzido por iECA como sexo feminino, idade, origem étnica, reações adversas anteriores, outras doenças alérgicas, tabagismo, obesidade, cirurgias das vias aéreas, trauma e imunossupressão em pacientes que receberam transplante renal ou cardíaco (CAMPO et al., 2013). O diagnóstico diferencial para urticária espontânea inclui, por exemplo, o estágio inicial de pênfigo bolhoso, sarna e outras reações a artrópodes, eritema figurado, Síndrome de Sweet e eritema elevatum diutinum; durante a gestação, também inclui erupções polimórficas da gravidez (Pruritic Urticarial Papules and Plaques of Pregnancy - PUPPP) e pênfigo gestacional. Lesões urticariformes individuais persistentes por mais de 24 horas (após marcação das bordas, observar a progressão) e com componente hemorrágico ou hiperpigmentação residual justificam avaliação histopatológica para descartar vasculite urticarial (WEDI et al., 2014).

Os principais medicamentos promotores de angioedema são os inibidores da enzima conversora de angiotensina (iECAs), antiinflamatórios não esteroidais (AINEs) e antidiabéticos orais (BERTAZZONI et al., 2013). A urticária espontânea aguda é promovida por medicamentos (principalmente AINEs), enquanto a urticária espontânea crônica, por pseudoalérgenos (especialmente AINEs) (WEDI et al., 2014). O angioedema induzido por iECA pode levar a inflamação severa das vias aéreas, potencialmente ameaçadora à vida, e apresenta diferentes graus de gravidade; até $20 \%$ pode ser fatal, afetando a laringe e o trato respiratório superior (CAMPO et al., 2013). Por razões ainda não elucidadas, o angioedema induzido por iECA se mostra mais prevalente entre pacientes imunossuprimidos após transplante cardíaco ou renal do que entre outros pacientes (ARONSON, 2006).

A urticária espontânea aguda é auto-limitada e geralmente tratada sintomaticamente. $\mathrm{Na}$ ausência de angioedema ameaçador ou sintomas gerais (hipotensão, sensação de globo na garganta, dispneia, náusea/vômito), antihistamínicos H1, possivelmente em doses aumentadas, são geralmente suficientes. Caso não haja resposta, a adição de corticosteroides orais (até $50 \mathrm{mg}$ de prednisolona equivalente por dia) por no máximo dez dias pode auxiliar. Os gatilhos identificáveis (medicamentos ou alérgenos) devem ser evitados e infecções agudas adequadamente tratadas. Em caso de sintomas ameaçadores à vida, internação é indicada. Em caso de sintomas ameaçadores como angioedema oral/ faríngeo, desregulação circulatória, dispneia, náusea e urticária generalizada, antihistamínicos endovenosos $\mathrm{H} 1$ (prometazina) e corticosteroides (dependendo da severidade dos sintomas, 100 a $250 \mathrm{mg}$ de prednisolona equivalente, possivelmente pode ser maior) devem ser administrados imediatamente. Rápida progressão em termos de choque anafilático deve ser contido através de rápida administração de epinefrina (WEDI et al., 2014).

No angioedema mediado por bradicinina, a retirada do medicamento promotor é imprescindível e bloqueadores do receptor de angiotensina II (BRA) são alternativa ao uso de iECA em pacientes que requerem inibição de angiotensina. Uso concomitante de iECAs e AINEs deve ser evitado em pacientes com histórico de angioedema, já que a combinação pode levar a episódios mais severos. Casos mais leves geralmente são tratados com anti-histamínicos (bloqueadores H1 e H2) e esteroides, com resolução dos sintomas dentro de 24 a 48 horas. Em casos moderados e graves, a intubação é eletiva para proteção das vias aéreas. O tratamento com epinefrina pode diminuir a taxa de edema, enquanto antihistamínicos e esteróides demonstraram pouco efeito. Nos casos com angioedema grave, os pacientes devem ser monitorados quanto ao comprometimento das vias aéreas e complicações fatais por causa do risco de recaídas, apesar da retirada do medicamento ofensivo (CAMPO et al., 2013). As principais características clínicas e manejo recomendado do quadro de urticária e angioedema se encontram no Quadro 6 para consulta rápida. 
Quadro 6 - Principais características clínicas e manejo recomendado de urticária e angioedema.

\begin{tabular}{|c|c|}
\hline \multicolumn{2}{|r|}{ Urticária e Angioedema } \\
\hline $\begin{array}{l}\text { Tempo para } \\
\text { início }\end{array}$ & $\begin{array}{l}\text { Urticária espontânea aguda ocorre } \\
\text { tipicamente dentro de } 30 \text { minutos após } \\
\text { exposição a fármaco promotor. Angioedema } \\
\text { medicado por bradicinina pode se apresentar } \\
\text { na primeira semana, ao longo dos primeiros } \\
90 \text { dias de tratamento com o medicamento } \\
\text { gatilho ou ser retardado em sete a dez anos } \\
\text { de uso. }\end{array}$ \\
\hline $\begin{array}{l}\text { Manifestações } \\
\text { cutâneas }\end{array}$ & $\begin{array}{l}\text { Aparecimento súbito de lesões elevadas } \\
\text { ou pápulas, intensamente pruriginosas em } \\
\text { quadros de urticária, com possibilidade de } \\
\text { angioedema associado em rosto, lábios, } \\
\text { extremidades e/ou genitálias. Inchaço não } \\
\text { prurítico da pele e de mucosas em caso de } \\
\text { angioedema por bradicinina. }\end{array}$ \\
\hline $\begin{array}{l}\text { Achados } \\
\text { cutâneos } \\
\text { adicionais }\end{array}$ & $\begin{array}{l}\text { Em caso de urticária espontânea aguda, } \\
\text { erupções de tamanhos variados e angioedema } \\
\text { concomitante em derme profunda e gordura } \\
\text { subcutânea; queimação e/ou dor moderada. } \\
\text { Angioedema por bradicinina pode ser } \\
\text { precedido por eritema marginatum e não } \\
\text { apresenta prurido. }\end{array}$ \\
\hline $\begin{array}{l}\text { Tempo para } \\
\text { resolução }\end{array}$ & $\begin{array}{l}\text { Urticária espontânea aguda geralmente } \\
\text { resolve-se em menos de } 24 \text { horas e } \\
\text { angioedema associado persiste por um a três } \\
\text { dias. Angioedema por bradicinina apresenta } \\
\text { curso prolongado. }\end{array}$ \\
\hline $\begin{array}{l}\text { Manifestações } \\
\text { sistêmicas } \\
\text { associadas }\end{array}$ & $\begin{array}{l}\text { Angioedema por bradicinina pode levar a } \\
\text { cenários sub-oclusivos em região abdominal, } \\
\text { com dor intensa, distúrbios da pressão arterial } \\
\text { e sintomas gastrintestinais. }\end{array}$ \\
\hline sriais & $\begin{array}{l}\text { Não foram encontrados nas referências } \\
\text { consultadas. }\end{array}$ \\
\hline $\begin{array}{l}\text { Principais } \\
\text { classes de } \\
\text { medicamentos } \\
\text { promotores }\end{array}$ & $\begin{array}{l}\text { Urticária espontânea aguda apresenta } \\
\text { antiinflamatórios não esteroidais (AINEs) } \\
\text { como principal classe promotora, enquanto } \\
\text { angioedema por bradicinina é promovido } \\
\text { principalmente por inibidores da enzima } \\
\text { conversora de angiotensina (iECAs), AINEs } \\
\text { e antidiabéticos orais. }\end{array}$ \\
\hline Mortalidade & $\begin{array}{l}\text { Angioedema por bradicinina pode atingir } \\
20 \% \text { de mortalidade. }\end{array}$ \\
\hline s̃os & $\begin{array}{l}\text { Em caso de angioedema por bradicinina, pode } \\
\text { ocorrer inflamação severa das vias aéreas. }\end{array}$ \\
\hline $\begin{array}{l}\text { Manejo } \\
\text { recomendado }\end{array}$ & $\begin{array}{l}\text { Urticária espontânea aguda é auto-limitada, de } \\
\text { manejo sintomático. Em caso de angioedema } \\
\text { associado a urticária ou por bradicinina, } \\
\text { não ameaçador à vida, anti-histamínicos; se } \\
\text { não houver boa resposta, corticosteroides } \\
\text { orais por no máximo dez dias. Retirada do } \\
\text { medicamento promotor é imprescindível. Em } \\
\text { caso de sintomas ameaçadores à vida, anti- } \\
\text { histamínicos e corticosteroides endovenosos } \\
\text { devem ser administrados imediatamente, } \\
\text { com contenção de choque anafilático por } \\
\text { administração de epinefrina em caso de } \\
\text { progressão. }\end{array}$ \\
\hline
\end{tabular}

Fonte: Dados da pesquisa.

\section{Conclusão}

O conhecimento das reações adversas a medicamentos permite a correta investigação da reação adversa sofrida pelo paciente e manejo adequado. A existência de documentos institucionais com as informações necessárias para execução da Farmacovigilância e, consequentemente Segurança do Paciente, fornece o embasamento científico necessário para tomada de decisões e manejo de quadros de incidentes relacionados a medicamentos. Os artigos escolhidos para a revisão de literatura deram origem a quadros informativos com características clínicas e manejo recomendado das farmacodermias abordadas neste estudo, com base nas informações disponíveis. A escolha por elaboração de quadros de fácil consulta com as informações obtidas a partir da revisão de literatura é resultado da necessidade de conhecimento detalhado por parte do profissional envolvido com farmacovigilância para identificar e manejar as RAMs cutâneas. Mesmo em literaturas de referência em reações adversas, ao consultar quais RAMs podem ser resultantes do uso de um medicamento, algumas farmacodermias são apenas citadas, sem detalhamento de lesões cutâneas ou sugestões de manejo clínico.

\section{Referências}

ADKINSON, N.F. et al. Middleton's allergy principles and practice. Philadelphia: Elsevier Saunders, 2014.

ARONSON, J.K. Meyler's side effects of drugs: the international encyclopedia of adverse drug reactions and interactions. Elsevier Science, 2006

BERTAZZONI, G. et al. Drug-induced angioedema: experience of Italian emergency departments. Int. Emerg. Med., v.9, n.4, p.455-462, 2014. doi: 10.1007/s11739-013-1007-x.

BHARDWAJ, A. S. et al. A case of vasculitis in a breast cancer patient treated with T-DM1. Seminars in Oncology, v.41, n.5, p.e39-e45, 2014. doi: 10.1053/j.seminoncol.2014.08.010.

BOUILLET, L. et al. Recurrent angioedema: diagnosis strategy and biological aspects. Euro. J. Dermatol., v.24, n.3, p.293-296, 2014. doi: 10.1684/ejd.2014.2276.

BRASIL. Documento de referência para o Programa Nacional de Segurança do Paciente. Ministério da Saúde; Fundação Oswaldo Cruz; Agência Nacional de Vigilância Sanitária. - Brasília: MS, 2014a.

BRASIL. Protocolo de Segurança na Prescrição, Uso e Administração de Medicamentos. Ministério da Saúde; Fundação Oswaldo Cruz; Agência Nacional de Vigilância Sanitária. Brasília: MS, 2014b.

CAMPO, P. et al. Angioedema induced by angiotensin-converting enzyme inhibitors. Cur. Opinion Allergy Clin. Immunol., v.13, n.4, p.337-344, 2013. doi: 10.1097/ACI.0b013e328362b835.

CHOI, D.; KANNAN, S.; LIM, H.W. Evaluation of patients with photodermatoses. Dermatol. Clin., v.32, n.3, p.267-275, 2014. doi: 10.1016/j.det.2014.03.006.

COLLINS-YODER, A.S. Angioedema: clinical presentations and pharmacological management. Dimensions Crit. Care Nurs., v.35, n.4, p.181-189, 2016. doi: 10.1097/DCC.0000000000000188.

DAWE, R.S.; IBBOTSON, S.H. Drug-induced photosensitivity. Dermatol. Clin., v.32, n.3, p.363-368, 2014. doi: 10.1016/j. det.2014.03.014.

FELDER, S. et al. Prognostic factors in outcome of angioedema in the emergency department. Allergy Asthma Proc., v.35, n.5, p.362-370, 2014. doi: 10.2500/aap.2014.35.3787. 
GARG, Y. et al. A rare case of isoniazid-induced erythroderma. Ind. J. Pharmacol., v.47, n.6, p.682, 2015. doi: 10.4103/02537613.169575

GÓMEZ-BERNAL, S. et al. Fotosensibilidad por tiazidas. Actas Dermo-Sifiliográficas, v.105, n.4, p.359-366. doi: 10.1016/j. ad.2013.01.010.

GRAU, R. G. Drug-induced vasculitis: new insights and a changing lineup of suspects. Current Rheumatol. Reports, v.17, n.12, 2015. doi: 10.1007/s11926-015-0545-9.

GROSSBERG, A.L. Update on pediatric photosensitivity disorders. Curr. Opinion Pediatr., v.25, n.4, p.474-479, 2013. doi: 10.1097/MOP.0b013e328362c2c3.

HEELAN, K.; SHEAR, N. H. Cutaneous drug reactions in children: an update. Pediatr. Drugs, v.15, n.6, p.493-503, 2013. doi: 10.1007/s40272-013-0039-z.

HONARI, G. Photoallergy. Rev. Environ. Health, v.29, n.3, p.233-242, 2014. doi: 10.1515/reveh-2014-0067.

HUSSEIN, M.R.A. Drug-induced skin reactions: a pathologist viewpoint. Cutaneous Ocular Toxicol., v.35, n.1, p.67-79, 2016. doi: 10.3109/15569527.2015.1015725.

IJAZ, N. et al. Cutaneous drug rashes. British J. Hosp. Med., v.76, n.11, p.166-169, 2015. doi: 10.12968/hmed.2015.76.11.C166.

JAFILAN, L.; JAMES, C. Urticaria and allergy-mediated conditions. Primary Care Clin. Office Practice, v.42, n.4, p.473483, 2015. doi: 10.1016/j.pop.2015.08.002.

KHALIL, P.N. et al. The formal requirements of algorithms and their implications in clinical medicine and quality management. Langenbeck's Arch. Surg., v.396, p.31-40, 2011. doi: 10.1007/ s00423-010-0713-3.

KOWALSKI, M.L.; WOESSNER, K.; SANAK, M. Approaches to the diagnosis and management of patients with a history of nonsteroidal anti-inflammatory drug-related urticaria and angioedema. J. Allergy Clin. Immunol., v.136, n.2, p.245-251, 2015. doi: 10.1016/j.jaci.2015.06.021.

KULTHANAN, K. et al. Clinical practice guideline for diagnosisi and management of urticaria. Asian Pacific J. Allergy Immunol., v.34, p.190-200, 2016.

KUMAR, S. et al. Imatinib mesylate induced erythroderma: a rare case series. J. Cancer Res. Therapeutics, v.11, n.4, p.993, 2015. doi: 10.4103/0973-1482.157341

LOSAPPIO, L. et al. Acute urticaria presenting in the emergency room of a general hospital. Euro. J. Int. Med., v.25, n.2, p.147150, 2014. doi: 10.1016/j.ejim.2013.11.003.

MARZANO, A.V.; BORGHI, A.; CUGNO, M. Adverse drug reactions and organ damage: The skin. Euro. J. Int. Med., v.28, p.17-24, 2016. doi: 10.1016/j.ejim.2015.11.017.

MICHELETTI, R.G.; WERTH, V.P. Small vessel vasculitis of the skin. Rheumatic Dis. Clin. North Am., v.41, n.1, p.21-32, 2015. doi: 10.1016/j.rdc.2014.09.006.

MISTRY, N. et al. A review of the diagnosis and management of erythroderma (Generalized Red Skin). Adv. Skin Wound Care, v.28, n.5, p.228-236. doi: 10.1097/01.ASW.0000463573.40637.73.
MONTEIRO, A.F.; RATO, M.; MARTINS, C. Drug-induced photosensitivity: photoallergic and phototoxic reactions. Clin. Dermatol., v.34, n.5, p.571-581, 2016. doi: 10.1016/j. clindermatol.2016.05.006.

NAYAK, S.; BASANTI, A. Adverse cutaneous drug reaction. Ind. J. Dermatol., v.53, n.1. p.2-8, 2008. doi: 10.4103/00195154.39732.

NOGUERA-MOREL， L.; HERNÁNDEZ-MARTÍN, Á.; TORRELO, A. Cutaneous drug reactions in the pediatric population. Pediatr. Clin. North Am., v.61, n.2, p.403-426, 2014. doi: 10.1016/j.pcl.2013.12.001.

OMS - Organização Mundial da Saúde. Patient Safety: Making health care safer. Genebra: OMS, 2017a.

OMS - Organização Mundial da Saúde. Safety of medicines: a Guide to Detecting and Reporting Adverse Drug Reactions - Why Health Professionals Need to Take Action. Genebra: OMS, $2017 \mathrm{~b}$.

OMS - Organização Mundial da Saúde. Essential medicines and health products. Genebra: OMS, 2017c.

OZUGUZ, P. et al. Erythroderma secondary to gliclazide: a case report. Cutaneous Ocular Toxicol., v.33, n.4, p.342-344, 2014. doi: 10.3109/15569527.2013.870188.

PINA, T.; BLANCO, R.; GONZÁLEZ-GAY, M.A. Cutaneous vasculitis: a rheumatologist perspective. Current Allergy Asthma Reports, v.13, n.5, p.545-554, 2013. doi: 10.1007/s11882-0130367-7.

RAMBHATLA, P.V. et al. Photosensitive disorders of the skin with ocular involvement. Clin. Dermatol., v.33, n.2, p.238-246, 2015. doi: 10.1016/j.clindermatol.2014.10.016.

ROUJEAU J.C.; STERN R.S. Severe adverse cutaneous reactions to drugs. New England J. Med., v.331, p.1272-1285, 1994. doi: 10.1056/NEJM199411103311906.

ROUJEAU, J.C. et al. Management of nonimmediate hypersensitivity reactions to drugs. Immunol. Allergy Clin. North Am., v.34, n.3, p.473-487, 2014. doi: 10.1016/j.iac.2014.04.012.

ROWE, C.J. et al. Warfarin-induced erythroderma: warfarininduced erythroderma. Aust. J. Dermatol., v.56, n.1, p.e15-e17, 2015. doi: 10.1111/ajd.12140.

SHARMA, G.; GOVIL, D. Allopurinol induced erythroderma. Indian J. Pharmacol., v.45, n.6, p.627, 2013. doi: 10.4103/02537613.121381

SONG, J.E.; SIDBURY, R. An update on pediatric cutaneous drug eruptions. Clin. Dermatol., v.32, n.4, p.516-523, 2014. doi: 10.1016/j.clindermatol.2014.02.005.

SWANSON, L.; COLVEN, R.M. Approach to the Patient with a Suspected Cutaneous Adverse Drug Reaction. Medical Clinics of North America, v. 99, n. 6, p. 1337-1348, nov. 2015. doi: 10.1016/j.mcna.2015.06.003.

TAN, G.F.L. et al. Causes and Features of Erythroderma. Ann. Academy Med. Singapore, v.43, n.8, p.391-394, 2014.

WEDI, B. et al. Urticaria. JDDG: J. Deutschen Dermatol. Gesellschaft, v.12, n.11, p.997-1009, 2014. doi: 10.1111/ ddg. 12441. 